\title{
How to Improve the Liveability in Cities: The Effect of Urban Morphology and Greening on Outdoor Thermal Comfort
}

\author{
Guglielmina Mutani ${ }^{1 *}$, Valeria Todeschi ${ }^{2}$, Simone Beltramino $^{3}$ \\ ${ }^{1}$ Responsible Risk Resilience Centre - R3C, Department of Energy, Politecnico di Torino. Turin, Italy \\ ${ }^{2}$ Future Urban Legacy Lab - FULL, Department of Energy, Politecnico di Torino. Turin, Italy \\ ${ }^{3}$ Responsible Risk Resilience Centre - R3C, Interuniversity Department of Regional and Urban Studies and Planning, \\ Politecnico di Torino. Turin, Italy
}

Corresponding Author Email: guglielmina.mutani@polito.it

https://doi.org/10.18280/ti-ijes.652-433

Received: 25 March 2021

Accepted: 16 May 2021

\section{Keywords:}

outdoor thermal comfort, urban morphology, green roofs, vegetated areas, neighborhood scale

\begin{abstract}
Extensive and intensive green roofs and vegetated walls should be used to improve the livability in cities, especially in densely built-up context, in order to optimize their contribution on energy savings and greenhouse gas emissions, improving thermal comfort conditions and ensuring a greater storm-water runoff. The aim of this study is to evaluate the effect of urban morphology and to quantify the impact of green surfaces and plants on outdoor thermal comfort conditions. The analysis was applied to six neighborhoods in the city of Turin, identified as typical districts with different building geometries, urban contexts and green presence. The outdoor thermal comfort conditions were assessed calculating a set of indicators, such as the predicted mean vote and the physiological equivalent temperature, with the support of ENVI-met tool. Retrofit scenarios were hypothesized, and outdoor thermal comfort conditions were investigated before and after the installation of green roofs and vegetated areas. The result allowed to understand how thermal comfort vary, considering the building geometry, urban morphology, and green areas in different zones of the city of Turin. By analyzing neighborhoods, it is possible to identify the optimal built environment that ensure better thermal comfort conditions. These models and tools could support urban planners in defining the best measures to improve the liveability and quality in the built environment considering local constraints and the real characteristics of the territory or in designing new neighborhoods.
\end{abstract}

\section{INTRODUCTION}

Rising temperatures and increasing urbanization in cities are trends that can play an important role in the fight against climate changes. Moreover, inside cities with high-density built environment, the urban heat island can cause a further increase of temperatures, making outdoor urban environments thermally stressful especially in the hot season [1].

To improve the quality of life in cities, the decrease of energy consumptions in buildings has to be associated with measures and technologies able to foster the reduction of greenhouse gas emissions, the mitigation of urban heat island effects and thermal comfort conditions [2].

Outdoor thermal comfort is strongly influenced by the built environment: building geometry, urban morphology and pavement materials $[2,3]$. According to the literature review on thermal comfort, the integration of green and vegetated elements into the built environment brings great benefits to urban comfort and provide ecosystem services to the population by improving local climate conditions with the evapotranspiration and more permeable surfaces for a better water management [4].

The aim of this work is to quantify the impact of green roof and vegetated areas on the outdoor thermal comfort in six neighborhoods with different urban morphologies located in the city of Turin (Italy). For each neighborhood, a scenario of green integration within the urban environment was investigated. As a function of the shape of the building, the roof characteristics and the urban morphology, best retrofit measures were identified to achieve the optimal thermal comfort conditions. The assessment was made taking into account 4 days that represent seasonal climate differences in order to evaluate how the improvement of greening affects urban thermal comfort; the results of this work can provide guidelines to support urban planners to improve the livability of outdoor spaces and thermal comfort conditions. Moreover, policy makers can use the results of this analysis to identify more effective strategies to implement building codes.

\section{STATE OF THE ART}

A considerable amount of literature has been published recently on the analysis of outdoor thermal comfort conditions in urban environments. These studies are presented in the following sections. In particular, this analysis was focused to identify the most used urban models and tools to evaluate the thermal comfort conditions together with the most common thermal comfort indexes.

\subsection{Urban climate models and tools}

In literature, there are many studies related to outdoor 
thermal comfort conditions and the methodologies and tools used to investigate it are quite complex and time consuming. Therefore, to offer a comprehensive overview on existing models and tools, the results of this work were synthetized in Table 1 . Table 1 presents a schematic summary of published articles on the evaluation of outdoor urban thermal comfort. Studies were investigated taking into consideration: in-situ measurement campaigns; the application of various models and tools (such as ENVI-met, CitySim, Rayman, and SOLWEIG); and thermal comfort indexes. In particular, the most commonly used thermal comfort indexes are: the predicted mean vote $(P M V)$, the predicted percentage dissatisfied $(P P D)$, the physiologically equivalent temperature $(P E T)$, the standard effective temperature (SET), the universal thermal climate index (UTCI), the index of thermal stress (ITS). The use of thermal comfort models is often accompanied with the evaluation of local climate conditions and in-situ measurement campaigns to verify the goodness of the results obtained. In some studies, [5-9] ENVI-met, Rayman and SOLWEIG were used associated with buildings energy-use models such as CitySim or GIS-based models considering also local climate data collected with measurement campaigns [1016]. In general, for thermal comfort analyses the most used tool is ENVI-met and in some works the goodness of the results is taken for granted [7,13-15], while in others it is made a comparison with the results of Rayman and SOLWEIG [5,
17-27]. Furthermore, the most used thermal comfort indexes are PET, PMV, and UTCI. These, are the indexes that best represent the outdoor thermal comfort conditions at neighborhood scale.

\subsection{Thermal comfort indexes}

Thermal comfort is "the state of mind that expresses satisfaction with the thermal environment and is assessed by subjective evaluation" (ANSI/ASHRAE Standard 55:2020) that is influenced by physical, physiological, psychological and other variables. In this work, thermal comfort will be used to evaluate the livability of different urban environments as a function of their urban morphology, construction materials and presence of green and vegetation. Then, thermal comfort indexes consider physiological and psychological people characteristics that represent their average data [28-36].

Currently, there are several outdoor thermal comfort (OTC) tools to simulate human perception. In this work thermal indexes based on the human energy balance [37, 38] were investigated using ENVI-met, which is the most used tool to investigate outdoor thermal comfort conditions. According to the literature review $[35,36]$, the most used three indexes based on a human thermal balance for outdoor thermal comfort were investigated.

Table 1. Outdoor thermal comfort simulations: models, tools and indexes

\begin{tabular}{|c|c|c|c|c|c|c|c|c|c|c|c|c|c|c|c|}
\hline \multirow[b]{2}{*}{ 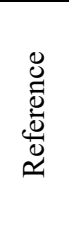 } & \multicolumn{8}{|c|}{ Models and tools } & \multicolumn{6}{|c|}{ Thermal comfort indexes } & \multirow[b]{2}{*}{ 踣 } \\
\hline & 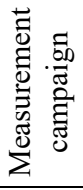 & 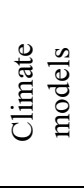 & 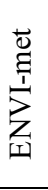 & $\stackrel{\Xi}{\Xi}$ & 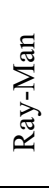 & $\begin{array}{l}\stackrel{0}{0} \\
\frac{1}{3} \\
0 \\
0\end{array}$ & 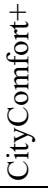 & $\sum_{j}^{\vdots}$ & $\underset{\Sigma}{\Sigma}$ & $\frac{\hat{2}}{2}$ & $\underset{2}{\mathbb{2}}$ & 预 & 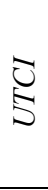 & $\underline{E}$ & \\
\hline$[5]$ & & $\bullet$ & $\bullet$ & & $\bullet$ & $\bullet$ & & & & & & & & & $\bullet$ \\
\hline [6] & - & $\bullet$ & & - & & & & & & & & & & & $\bullet$ \\
\hline [7] & & $\bullet$ & & $\bullet$ & & & & & & & & & & - & \\
\hline [8] & & $\bullet$ & $\bullet$ & $\bullet$ & & $\bullet$ & & & & & $\bullet$ & & $\bullet$ & & $\bullet$ \\
\hline [9] & & & $\bullet$ & $\bullet$ & $\bullet$ & & & & & & & & & & $\bullet$ \\
\hline [10] & - & - & & & & & & & & & & & - & & \\
\hline [11] & $\bullet$ & & & & & & & & & & $\bullet$ & & & & \\
\hline [12] & $\bullet$ & & & & & & & & & & & & & & $\bullet$ \\
\hline [13] & $\bullet$ & & . & & & & & & $\bullet$ & & $\bullet$ & $\bullet$ & $\bullet$ & & \\
\hline [14] & $\bullet$ & & $\bullet$ & & & & & & $\bullet$ & & & & & & $\bullet$ \\
\hline [15] & $\bullet$ & & $\bullet$ & & & & & & & & $\bullet$ & & & & \\
\hline [16] & $\bullet$ & & & & & & & & & & & & & & $\bullet$ \\
\hline [17] & & & - & & & & & & $\bullet$ & & $\bullet$ & & & & \\
\hline [18] & & & $\bullet$ & & & & & & & & $\bullet$ & & & & \\
\hline [19] & & & $\bullet$ & & & & & & & & $\bullet$ & & & & $\bullet$ \\
\hline [20] & & & $\bullet$ & & $\bullet$ & & & & $\bullet$ & & $\bullet$ & & & & \\
\hline [21] & & & - & & - & & & & & & - & & & & \\
\hline [22] & & - & $\bullet$ & & $\bullet$ & & & & & & $\bullet$ & & & & $\bullet$ \\
\hline [23] & & $\bullet$ & & & $\bullet$ & $\bullet$ & & & & & $\bullet$ & & & & $\bullet$ \\
\hline [24] & & & & & $\bullet$ & & & & & & $\bullet$ & & & & $\bullet$ \\
\hline [25] & - & & & $\bullet$ & & & & & & & $\bullet$ & & & & \\
\hline [26] & $\bullet$ & & & $\bullet$ & & & & & & & $\bullet$ & & - & & \\
\hline [27] & & & & & $\bullet$ & & & & & & & & $\bullet$ & & $\bullet$ \\
\hline [28] & & & & & & $\bullet$ & & & & & & & & & $\bullet$ \\
\hline [29] & & $\bullet$ & & & & & & & & & & & & & $\bullet$ \\
\hline [30] & $\bullet$ & $\bullet$ & & & & & & & & & & & & & $\bullet$ \\
\hline [31] & & & & & & & - & & & & & & & & $\bullet$ \\
\hline [32] & & - & & & & & & & & & & - & & & $\bullet$ \\
\hline [33] & & & $\bullet$ & & & & & & & & & $\bullet$ & & & \\
\hline [34] & & - & & & & & & & & - & & & & & \\
\hline
\end{tabular}

* The mean radiant temperature $T_{m r t}$ (in grey) is one of the main variables used to calculate thermal comfort indexes 
The predicted mean vote $(P M V)$ is based on a simple human thermal balance in controlled steady-state conditions and on seven-points thermal sensation scale. The $P M V$ is evaluated with the heat exchanges between the human body and the environment with one-node model not considering the thermoregulatory mechanisms within the different layers of the body and it was adapted to outdoor conditions with KlimaMichel-Modell adding the short and longwave radiations fluxes and typical outdoor activities and clothing.

The Physiologically Equivalent Temperature $(P E T)$ is based on Munich Energy-balance Model for Individuals (MEMI) a two-node model with energy balance equations between the human body core, its skin and the outdoor environment in steady-state conditions. The PET is defined as the air temperature (without wind speed and solar radiation) at which the heat balance of the human body is maintained with the same core and skin temperatures under the actual environment conditions.

The Universal Thermal Climate Index (UTCI) is based on Fiala multi-node model (i.e. 15 nodes) and it can evaluate the physiological response of human body in quasi-transient conditions and in various outdoor thermal environments, including extreme weather conditions. UTCI can be defined as the air temperature causing the same response as actual conditions.

For all these three indexes $P M V, P E T$ and $U T C I$, one of the main variables to evaluate the thermal comfort condition is the mean radiant temperature $T_{m r t}$. The $T_{m r t}$ is defined as the uniform temperature of an imaginary enclosure in which the radiant heat transfer from the human body is equal to the radiant heat transfer in the actual non-uniform enclosure (EN ISO 7726:2001). $T_{m r t}$ has a strong influence on thermophysiological comfort indices such as the PET or the PMV. Usually, the urban climate tools such as ENVI-met, SOLWEIG and CitySim simulate the $T_{m r t}$ (in K) according to Eq. (1):

$$
T_{m r t}=\sqrt[4]{\frac{\sum_{i=1}^{6} W_{i} \cdot\left(a_{p} \cdot K_{i}+a_{l} \cdot L_{i}\right)}{a_{l} \cdot \sigma}}
$$

where: $W_{i}$ is a direction-dependent weighting factor, it depends on the position and orientation of the person; $K_{i}$ is the short-wave radiation fluxes received by a standard person; $L_{i}$ is the long wave radiation fluxes received by a standard person; $a_{p}$ is the absorption coefficient of a clothed human body for short-wave radiation (standard value 0.7 ) and $a_{l}$ is the absorption coefficient of a clothed human body for long-wave radiation (standard value 0.97); $\sigma$ is the Stefan-Boltzmann constant $\left(5.67 \cdot 10^{-8} \mathrm{Wm}^{-2} \mathrm{~K}^{-4}\right)$.

The $T_{m r t}$ (in $\mathrm{K}$ ) can be also calculated using a GIS-based model [11] according to Eq. (2) that is a method used in CityComfort+ [34]. The input data were elaborated using GIS tools in order to simplify the simulation using few urban variables such as the sky view factor $(S V F)$ and the urban canyon height-to-width ratio $(H / W)$.

$$
T_{m r t}=\sqrt[4]{\frac{\left(\begin{array}{c}
a_{p} \cdot E_{s o l} \cdot F_{s o l \rightarrow p}+\varepsilon_{s k y} \cdot E_{s k y} \cdot F_{s k y \rightarrow p^{+}} \\
+\varepsilon_{u r b} \cdot E_{u r b} \cdot F_{u r b \rightarrow p}
\end{array}\right)}{\sigma}}
$$

where: $a_{p}$ is the absorption coefficient of a clothed human body for short-wave radiation (i.e. standard value 0.7 ); $\varepsilon_{s k y}$ is emissivity of the sky (0-1) elaborated knowing the dewpoint temperature; $\varepsilon_{u r b}$ is the emissivity of surface material (0-1) [37-39]; $E_{\text {sol }}$ is the direct and diffuse solar irradiance $\left(\mathrm{W} / \mathrm{m}^{2}\right)$, the direct quota was calculated knowing the shadows as a function of the solar height in each hour and the urban canyon dimensions $H / W[40,41] ; E_{\text {sky }}$ is the long-wave radiation intensity of the sky $\left(\mathrm{W} / \mathrm{m}^{2}\right)$ elaborated according to [8]; $E_{\text {urb }}$ is the long-wave radiation intensity of urban surfaces $\left(\mathrm{W} / \mathrm{m}^{2}\right)$ elaborated according to [8]; $F_{s o l \rightarrow p}$ is the view factor between the short-wave sources and a person (0-1) elaborated with GIS tools; $F_{s k y \rightarrow p}$ is the view factor between the visible sky and a person $(0-1)$ elaborated with GIS tools; $F_{u r b \rightarrow p}$ is the view factor between urban surfaces and a person (0-1) elaborated with GIS tools; $\sigma$ is the Stefan-Boltzmann constant $\left(5.67 \cdot 10^{-}\right.$ $\left.{ }^{8} \mathrm{Wm}^{-2} \mathrm{~K}^{-4}\right)$.

\subsubsection{The Predicted Mean Vote $(P M V)$}

The $P M V$ is one of the most used thermal index and it is based on the thermal balance of human body and empirical data. The $P M V$ depends on air temperature, relative humidity, air speed, metabolic rate, and clothing insulation. It is based on the balance according to EN ISO 7730:2005 standard "Ergonomics of the thermal environment - Analytical determination and interpretation of thermal comfort using calculation of the $P M V$ and $P P D$ indices and local thermal comfort criteria" that reports the personal parameters, physical parameters and the main equations used to evaluate the $P M V$ index. ENVI-met calculates the $P M V$ according to Fangers and German standards VDI 3787-2:2008 [42], and requires the following input: (i) meteorological parameters: air temperature, mean radiant temperature, water vapour pressure, and local wind speed; and (ii) personal settings: clothing insulation, mechanical energy production of the body, and mechanical work factor. Eq. (3) shows how ENVI-met calculates the $P M V$ :

$$
\begin{gathered}
P M V=\left[0.028+0.303^{\left(-0.036 \cdot \frac{M}{A_{D u}}\right)}\right] \cdot\left(\frac{H}{A_{D u}}-E_{d}-\right. \\
\left.E_{S W}-E_{r e}-L-R-C\right)
\end{gathered}
$$

where:

- $\frac{M}{A_{D u}}$ and $\frac{H}{A_{D u}}$ are used to quantify the body energy production where $A_{D u}$ is the skin surface area; the first term is energy production of the body related to $1 \mathrm{~m}^{2}$ of skin and depends on the persons activity, the second term is the produced energy not used for mechanical work.

- $\quad E_{d}$ and $E_{s w}$ are used to quantify the skin water and the vapour exchange; the first term is the amount of vapour diffusing directly through the skin; the second term is cooling effect of liquid sweat evaporating from skin.

- $\quad E_{r e}$ and $L$ are used to quantify the energy exchange through breathing; the first term is the energy lost by humidifying the air in the respiratory system; the second term is the energy lost and/or gained through heat exchange with the breathed air within the body.

- $\quad R$ and $C$ are used to quantify the energy exchange at body surface; the first term is the radiative energy balance of the body and depends on the clothing thermal insulation, the temperature of the clothing, and the mean radiative temperature; the second term is the energy exchange through convection and depends on the clothing thermal insulation, the turbulent heat transfer coefficient for heat between clothing and air, the temperature of the clothing, 
the air temperature, and the wind speed considering the walking velocity of the person.

\subsubsection{The Physiological Equivalent Temperature (PET)}

The PET is a thermal comfort index calculated according to the Munich Energy Balance Model for Individuals (MEMI) [43] that is the energy balance for the human body indicated in Eq. (4). It depends on skin, body and clothing temperatures, and the sweat rate; these parameters are calculated taking into account all incoming and outgoing heat fluxes between human body and outdoor urban environment [40].

$$
M+W+C+R+E_{d}+E_{r e}+E_{s w}+S=0
$$

where: $M$ is the metabolic activity, $W$ is the physical work output, $C$ is the convective heat flow, $R$ is the net radiation of the body, $E_{d}$ is the amount of vapour diffusing directly through the skin, $E_{r e}$ is the energy lost by humidifying the air in the respiratory system, $E_{s w}$ is cooling effect of liquid sweat evaporating from skin, and $S$ is the storage heat flow for heating or cooling the body mass.

Knowing the skin and core temperatures, the MEMI balance can be solved to evaluate $P E T$ that is the air temperature $T_{a}$ with $v=0.1 \mathrm{~m} / \mathrm{s}, v p=12 \mathrm{hPa}$ and $T_{\mathrm{mrt}}=T_{\mathrm{a}}$. ENVI-met calculates $P E T$ according to a new model introduced by [44] The main improvements refer to: (i) turbulent exchange coefficients for heat and water vapour fluxes calculated with the internal air velocity and the outdoor value; (ii) the sweat rate and the amount of sweat on the skin is set to zero when starting to calculate the indoor environments.

\subsubsection{The Universal Thermal Climate Index (UTCI)}

According to Eq. (5), the UTCI is defined as the air temperature $T_{a}$ of the reference condition causing the same model response as actual conditions, solving a $6^{\text {th }}$ order polynomial regression as function of climate conditions:

$$
\begin{aligned}
U T C I=f\left(T_{a} ; T_{m r t} ; v_{a} ; v_{p}\right) \\
=T_{a}+\text { Off } \operatorname{set}\left(T_{a} ; T_{m r t} ; v_{a} ; v_{p}\right)
\end{aligned}
$$

where: the Offset is the deviation of UTCI from air temperature, $T_{a}$ and $T_{m r t}$ are the air and mean radiant temperatures, $v_{a}$ is the wind speed, $v_{p}$ is the water vapour pressure.

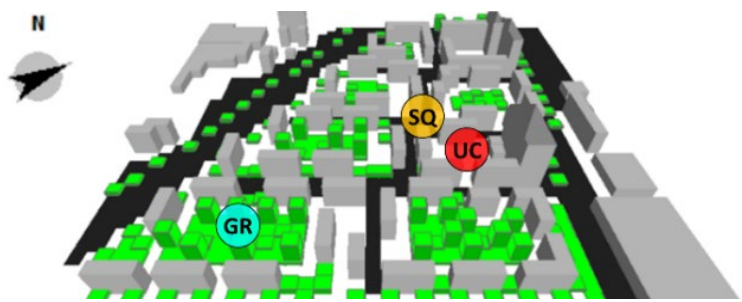

(a) Arquata

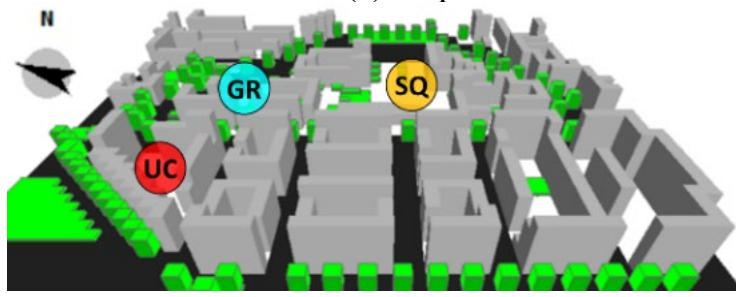

(c) Mediterraneo
In ENVI-met, UTCI index leads some limits into the calculations: (i) the wind speed is limited to a range of $0.5-17$ $\mathrm{m} / \mathrm{s}$ at $10 \mathrm{~m}$ height; (ii) the height reference of wind speed is $10 \mathrm{~m}$, while the outdoor thermal comfort parameters are usually calculated at 1-2 m.

\section{MATERIALS AND METHOD}

In this work, the effect of vegetation and green roofs on outdoor thermal comfort in six neighborhoods located in the city of Turin (Italy) that have different urban morphologies was investigated [45]. According to the literature review, ENVI-met is based on CFD models and it is one of the most used tools to analyze thermal comfort conditions in urban environment, since it is able to consider the effect of vegetation and evapotranspiration. Therefore, ENVI-met was used in this work to investigate the local climate conditions and the outdoor thermal comfort in six neighborhoods identified as case studies. The analysis was carried out on neighborhoods with different urban characteristics. Each neighborhood was designed in ENVI-met using grid cells with a resolution of $10 \times 10$ meters; this resolution was accurate enough to describe the six zones but not too detailed to increase too much the simulation times. In ENVI-met the wind speed and direction were assumed constant (with daily average values) while air temperature and relative humidity were set with the hourly values of the nearest weather station. Since ENVI-met it is a "holistic" three-dimensional model, it takes a long time to simulate outdoor thermal comfort conditions and in this work each neighborhood simulation required from 9 to 11 hours. The simulations were done taking into account the hottest day (summer), the coldest day (winter) and an average reference day for spring and for autumn. In particular, the first simulation aims to describe the business-as-usual $\left(\mathrm{S}_{\mathrm{BAU}}\right)$ scenario; then, after mitigation interventions, such as green roofs $\left(\mathrm{S}_{\text {GREEN }}\right)$, the effect of vegetation and green roofs on outdoor thermal comfort was quantified by calculating $T_{m r t}$, PMV, PET and UTCI. The output of these simulations will allow to analyze the liveability in different neighborhoods and how it depends on the urban form and on the use of mitigation measures.

\subsection{Case study}

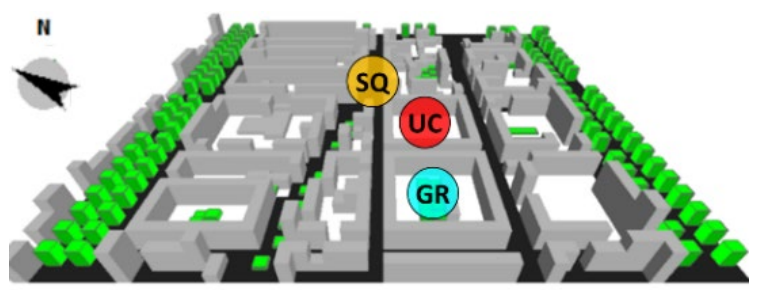

(b) Crocetta

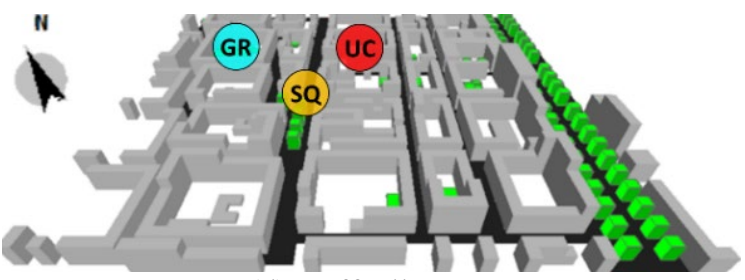

(d) Raffaello 


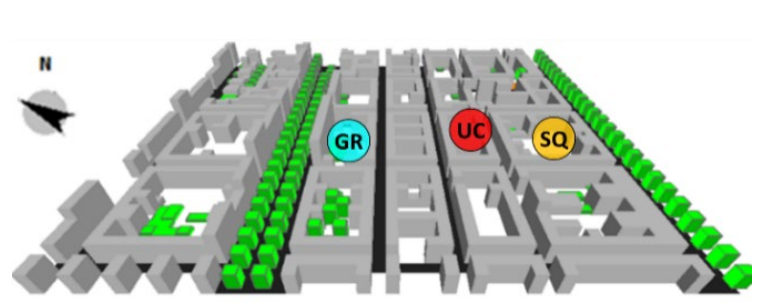

(e) Sacchi

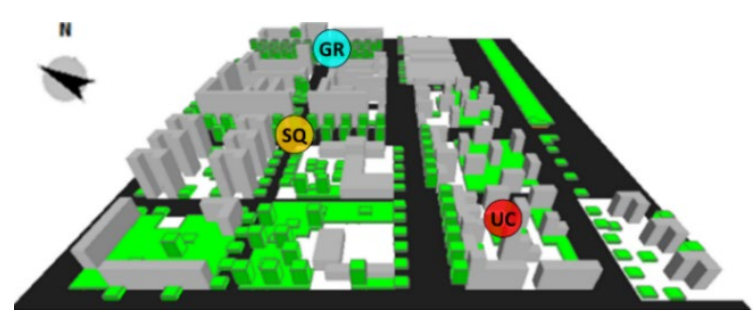

(f) Villaggio Olimpico

Figure 1. Six neighborhoods with the identification of specific points: $U C=$ urban courtyard, GR $=$ green area, $\mathrm{SQ}=$ square

Table 2. Neighborhoods characteristics (in brackets the number of trees per $10,000 \mathrm{~m}^{2}$ was indicated)

\begin{tabular}{ccccccc}
\hline Neighborhoods & Arquata & Crocetta & Mediterraneo & Raffaello & Sacchi & Villaggio Olimpico \\
\hline Inhabitants & 1,756 & 3,703 & 4,718 & 4,827 & 4,223 & 2,803 \\
Extension of the area $\left[\mathrm{m}^{2}\right]$ & 108,925 & 199,250 & 182,461 & 182,418 & 204,717 & 294,409 \\
Building density (BD) $\left[\mathrm{m}^{3} / \mathrm{m}^{2}\right]$ & 3.56 & 5.86 & 6.96 & 8.10 & 7.72 & 4.13 \\
Height-to-width ratio (H/W) [m/m] & 0.27 & 0.52 & 0.62 & 0.57 & 0.60 & 0.34 \\
Concrete light pavement [\%] & 6.13 & 0.00 & 11.64 & 0.00 & 0.00 & 4.27 \\
Concrete grey pavement [\%] & 20.63 & 24.28 & 13.24 & 28.60 & 27.76 & 14.37 \\
Asphalt [\%] & 43.50 & 51.24 & 49.72 & 36.44 & 35.92 & 45.47 \\
Grass [\%] & 10.31 & 1.28 & 8.08 & 2.36 & 1.72 & 18.40 \\
Buildings [\%] & 19.44 & 23.20 & 17.32 & 32.60 & 34.60 & 17.49 \\
Building coverage ratio (BCR) [\%] & 0.18 & 0.28 & 0.24 & 0.38 & 0.40 & 0.16 \\
Trees with height of $15 \mathrm{~m} *[\%]$ & $1.9(2.75)$ & $4.6(5.77)$ & $3.9(5.37)$ & $2.0(2.69)$ & $2.9(3.52)$ & $3.4(4.31)$ \\
Trees with height of 5 m * [\%] & $6.0(8.81)$ & $1.4(1.71)$ & $0.8(1.10)$ & $1.7(2.36)$ & $2.4(2.88)$ & $1.2(1.56)$ \\
\hline
\end{tabular}

The analysis was carry out in six neighborhoods identified as homogeneous zones with different building characteristics and urban contexts [45]. By analyzing these neighborhoods with a dimension of about $400 \times 400$ meters- it was possible to identify the sustainable urban form that ensures higher thermal comfort conditions. The neighborhoods that have been analyzed were Arquata, Crocetta, Raffaello, Sacchi, Mediterraneo and Villaggio Olimpico (Figure 1). From Figure 1 it is possible to observe different urban forms of the neighborhoods defined by the blocks of buildings in grey. The type of soil was indicated as follows: in black the asphalt (albedo $=0.13$ ), in green the vegetated areas and grass (albedo $=0.25)$ and in white grey or light concrete surfaces (albedo $=0.35$ ); the trees were represented as green blocks.

In addition, in each neighborhood three points with different urban characteristics have been identified -points in urban courtyards (UC, in red), points in green areas (GR, in blue) and points in squares (SQ, in yellow)- in which the comfort conditions have been analyzed. In Table 2 the main characteristics of each neighborhood, such as quantities of the type of soil and the presence of trees, have been indicated. Some recent neighborhoods (Arquata, Mediterraneo and Villaggio Olimpico) present more grass coverage and a low footprint of the built-up area, vice versa the neighborhoods with a more traditional conformation (Crocetta, Raffaello and Sacchi) are more densely urbanized. In general, it is possible to observe for all districts, the high values of street surfaces covered with asphalt between (between 36 and 51\%), even in the historical districts of Crocetta, Sacchi and Raffaello.

Regarding local climate conditions, a set of hourly meteorological data from the 'Politecnico di Torino' weather station was used to investigate local climate conditions. The assessment was done for the hottest day (summer, August $7^{\text {th }}$ ), the coldest day (winter, January $1^{\text {st }}$ ) and an average reference day for spring and for autumn (March $27^{\text {th }}$ and November $9^{\text {th }}$ ) in 2015. The hottest day and the coldest day of the year have been selected to evaluate the outdoor thermal comfort conditions in extreme conditions. Turin has a moderately continental climate, characterized by cold and humid winters, and hot and humid summers.

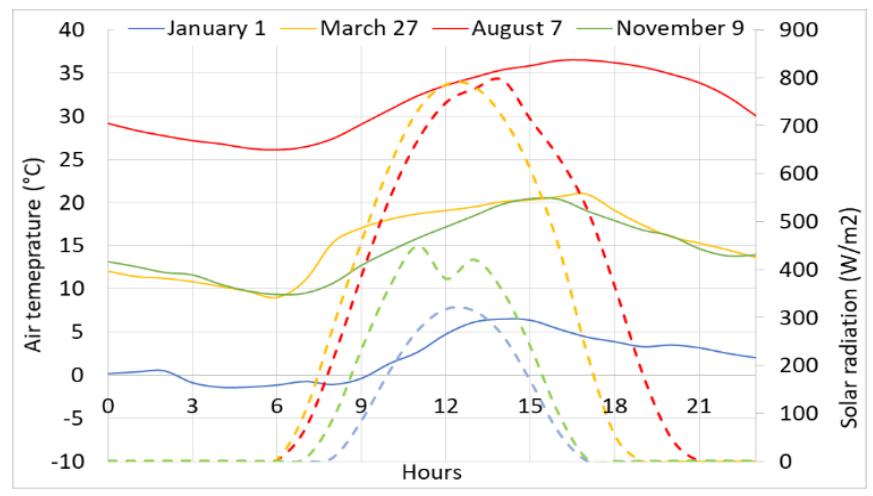

Figure 2. Air temperature (primary axis, solid line) and solar radiation (secondary axis, dashed line) with hourly detail for typical days (year 2015)

From Figure 2 it is possible to see different trend and intensity of solar radiation that affects the air temperature. In addition, the hotter the air the lower the relative humidity and vice versa, in the case of the summer day, where temperatures are higher, the accumulation in the air of water vapor is favored, raising the absolute humidity for evaporation and evapotranspiration from moist soil and vegetation. In all four days that have been chosen, the wind speed always presents low values (varies between 0.9 and $1.9 \mathrm{~m} / \mathrm{s}$ ), this due to the geographical position in which the city of Turin is located: in the Po Valley and surrounded by the Alps.

\section{RESULTS AND DISCUSSION}

Thermal comfort simulations were carried out for four typical days. In ENVI-met, with the support of Bio-met, the $T_{m r t}$ and three thermal comfort indices (PMV, PET and UTCI) 
were calculated at 1 meter above the ground for a person with 35 years old, male, weight of $75 \mathrm{~kg}$, height of $1.75 \mathrm{~m}$, taking into account the following input data: clothing insulation: 0.5 clo or $0.08 \mathrm{~m}^{2} \mathrm{~K} / \mathrm{W}$ (typical summertime clothing), 1 clo or $0.015 \mathrm{~m}^{2} \mathrm{~K} / \mathrm{W}$ (typical midseason clothing), 1.5 clo or 0.23 $\mathrm{m}^{2} \mathrm{~K} / \mathrm{W}$ (typical wintertime clothing); metabolic rate: 1.9 met or $110 \mathrm{~W} / \mathrm{m}^{2}$ (walking at $0.56 \mathrm{~m} / \mathrm{s}$ ).

\subsection{Thermal comfort analysis at a neighborhood scale}

In order to investigate the local climate conditions during summer, winter and mid-season, ENVI-met was used to describe the spatial distribution of the $T_{m r}$ in different urban contexts. Figure 3 shows an example of the analysis made in each neighborhood. In particular, in Mediterraneo three points were selected (see Figure 1) to evaluate the outdoor thermal comfort both in different local climate conditions (winter and summer) and in three different areas (GR is a point located in green area surrounded by buildings, SQ is a point located in an open space (without shading), UC is a point located in area with concrete pavement area surrounded by buildings).

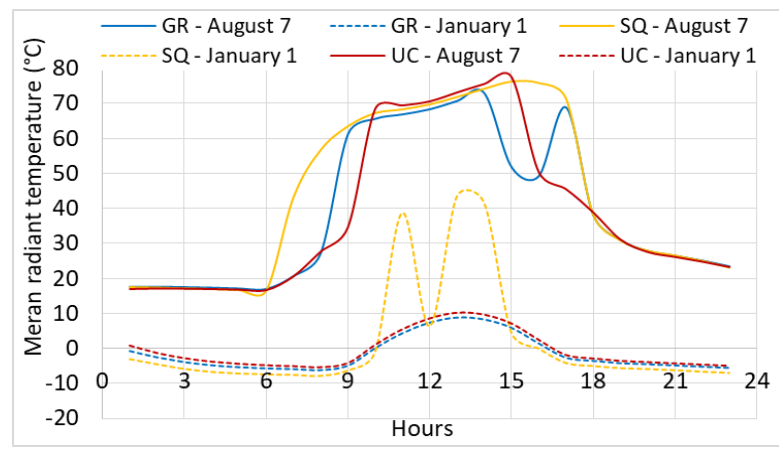

Figure 3. Hourly values of the $T_{m r}$ in 'Mediterraneo'

In Figure 3 it is possible to observe how the $T_{m r t}$ vary depending on the location in the neighborhood. GR and UC points, which were surrounded by buildings, have lower temperatures in some hours of the day (mainly in the morning and the afternoon) due to shading. In addition, the variations of $T_{m r t}$ depend on the reference season and in particular the greater incidence of shading in summer, where at $3 \mathrm{pm}$ the temperature drops drastically and then rises again around $5 \mathrm{pm}$. By contrast, during the winter day there is no variation.

\subsubsection{Mitigation strategies}

One of the strategies to mitigate the urban heat island effects and improve the liveability and quality of urban environments is the use of greenings in built-up areas such as green roofs, vegetation areas and trees. There are many benefits from the use of greenery in neighborhoods: air temperature reductions, outdoor thermal comfort improvements, energy savings for space cooling, lower greenhouse gas emissions, better air quality and urban space liveability improvements, storm-water run-off reductions, and aesthetic and social benefits [46].

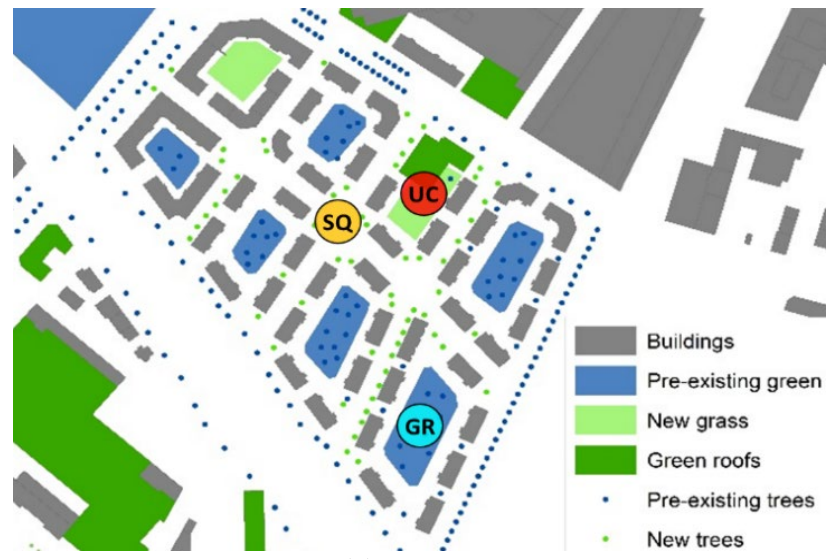

(a) Arquata

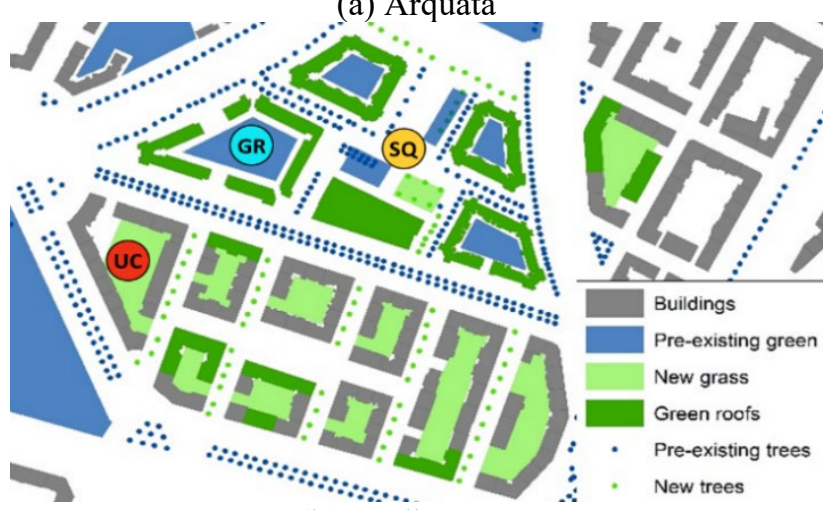

(b) Mediterraneo

Figure 4. Mitigation strategies: $\mathrm{S}_{\mathrm{BAU}}$ and $\mathrm{S}_{\mathrm{GREEN}}$

Since urban variables significantly affect thermal comfort, two neighborhoods that had different values of urban parameters (see Table 2) have been selected to evaluate the effect of mitigation strategies in different urban environment: Mediterraneo and Arquata (Figure 4). Table 3 shows the increase (in \%) of green surfaces and trees comparing the actual scenario $\left(\mathrm{S}_{\mathrm{BAU}}\right)$ and the new one $\left(\mathrm{S}_{\mathrm{GREEN}}\right)$ and the consequent improvements of outdoor thermal comfort conditions by evaluating PET, PMV and UTCI. The average daily variation of PET, PMV and UTCI for August $7^{\text {th }}, 2015$ (from 8 am to $6 \mathrm{pm}$ ) for two points (in Arquata and in Mediterraneo UC points, see Figure 4) was shown in Table 3. It is possible to observe that greater improvement of the indexes are visible in Mediterraneo neighborhood due to more relevant mitigation action. However, the average daily variation of all the indexes improves, highlighting how urban greenery are effective in improving thermal comfort in urban environments.

Table 3. Analysis of outdoor thermal comfort condition using mitigation strategies

\begin{tabular}{lccccccc}
\hline Neighborhood & Green areas (\%) & Green roofs (\%) & Trees $(\%)$ & PET $\left({ }^{\circ} \mathrm{C}\right)$ & PMV $(-)$ & UTCI $\left({ }^{\circ} \mathrm{C}\right)$ & Simulation time \\
\hline Mediterraneo & +7.8 & +29.3 & +2.0 & $-1.47(-2.20)$ & $-0.12(-0.17)$ & $-0.36(-0.68)$ & 11 hours \\
\hline Arquata & +1.1 & +22.2 & +2.6 & $-0.57(-1.05)$ & $-0.09(-0.15)$ & $-0.35(-0.59)$ & 9 hours \\
\hline
\end{tabular}

* In brackets the maximum difference between $\mathrm{S}_{\mathrm{BAU}}$ and $\mathrm{S}_{\mathrm{GREEN}}$ is indicated

Figure 5 shows how PET and UTCI change during the day by comparing the $\mathrm{S}_{\mathrm{BAU}}$ and $\mathrm{S}_{\mathrm{GREEN}}$ scenarios for different points in Arquata and Mediterraneo (see Figure 4). It is possible to observe an improvement of outdoor thermal comfort by using trees and green areas especially in Mediterraneo, where a large quota of green areas and roofs was inserted (see Table 3 ). 


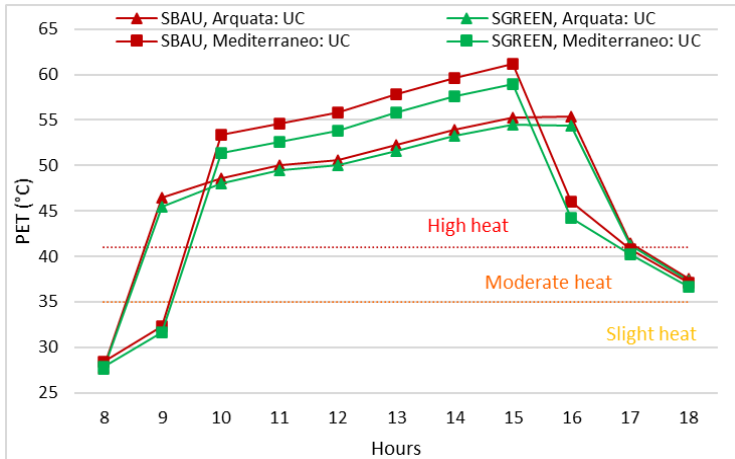

(a) Hourly values of $\operatorname{PET}\left({ }^{\circ} \mathrm{C}\right)$ at specific points (UC)

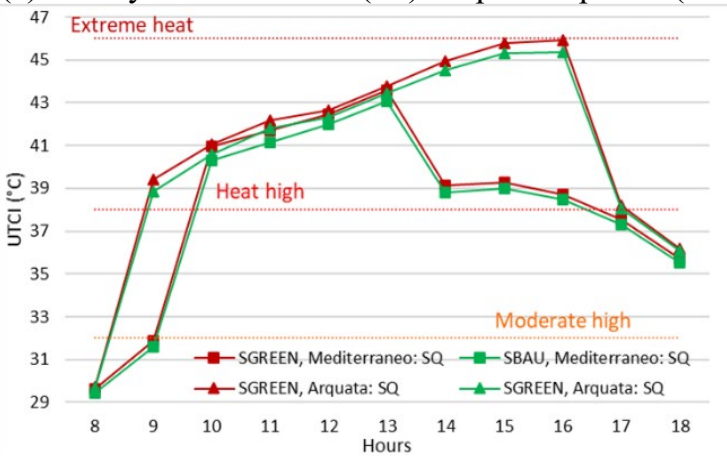

(b) Hourly values of $\operatorname{UTCI}\left({ }^{\circ} \mathrm{C}\right)$ at specific points (SQ)

Figure 5. Comparison between $\mathrm{S}_{\mathrm{BAU}}$ and $\mathrm{S}_{\mathrm{GREEN}}$ on August $7^{\text {th }}, 2015$

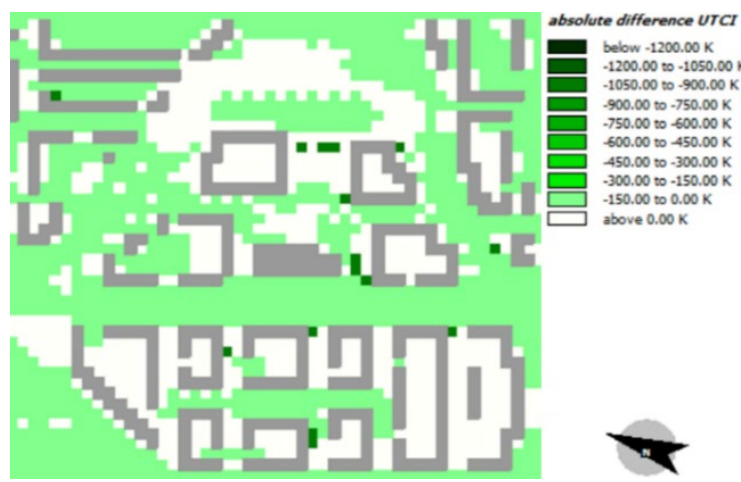

(a) Mediterraneo: absolute difference UTCI at $1 \mathrm{pm}$

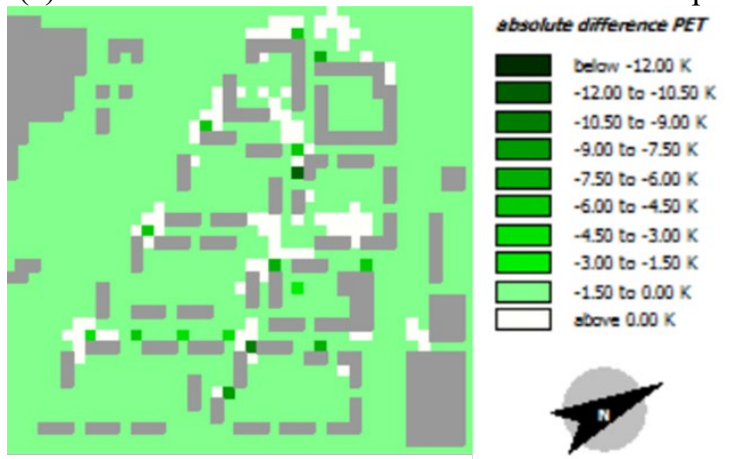

(b) Arquata: absolute difference PET at $5 \mathrm{pm}$

Figure 6. Comparison between $\mathrm{S}_{\mathrm{BAU}}$ and $\mathrm{S}_{\mathrm{GREEN}}$ on August $7^{\text {th }}, 2015$

Figure 6 shows the absolute difference of UTCI and PET (in walking at $2 \mathrm{~km} / \mathrm{h}$ ) for August $7^{\text {th }}, 2015$ in Mediterraneo and Arquata neighborhoods considering two scenarios ( $\mathrm{S}_{\mathrm{BAU}}$ and $\mathrm{S}_{\text {GREEN }}$ ). According to the shape of the roofs and to the type of outdoor surfaces, green roofs, green areas and trees were used to improve the quality of urban environment. The analysis shows an improvement in external thermal comfort conditions as result of green mitigation strategies. In particular, there was a slight overall improvement throughout the neighborhood, and the main progresses were particularly visible where the new green areas have been inserted.

\subsection{The effect of urban morphology on thermal comfort}

The relation between outdoor thermal comfort conditions and urban morphology was investigated using two parameters: (i) the building density $(B D)$ that is the ratio between the total volume of the buildings and the building block area; the higher the value, the denser the urban context; and (ii) the urban canyons height-to-width ratio $(H / W)$ that is the ratio between the building height and the distance between buildings.

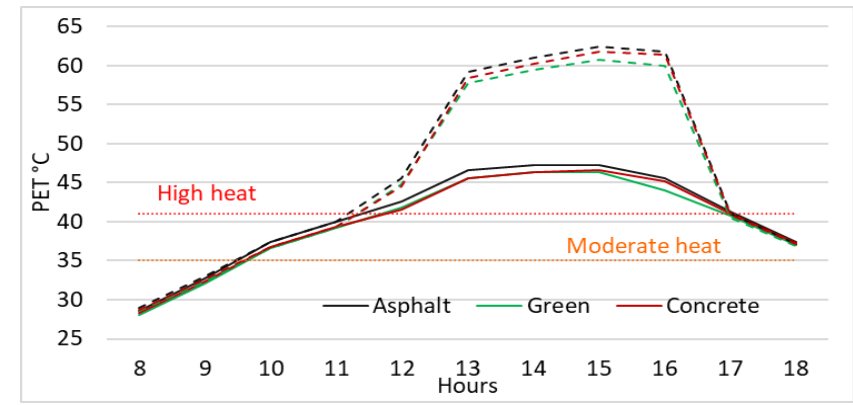

Figure 7. $P E T$ for August $7^{\text {th }}, 2015$ in two courtyards (typical for the city of Turin) with $H / W=1.2$ (continuous line) and $H / W=0.7$ (dotted line)

In the first part of this work, the analysis of thermal comfort conditions with different type of outdoor surfaces and dimensions of urban canyon and courtyard (specific values of each point identified in the neighborhood) have been investigated. Figure 7 shows the $T_{m r t}$ in two courtyards with $\mathrm{H} / \mathrm{W}=1.2$ (continuous line) and $\mathrm{H} / \mathrm{W}=0.7$ (dotted line) for August $7^{\text {th }}, 2015$. With high values of $\mathrm{H} / \mathrm{W}$ there was a greater shading, and $P E T$ values were slightly lower than $\mathrm{H} / \mathrm{W}=0.7$. The type of pavement also affects outdoor thermal comfort; in fact, lower values of $P E T$ were obtained for with green areas.

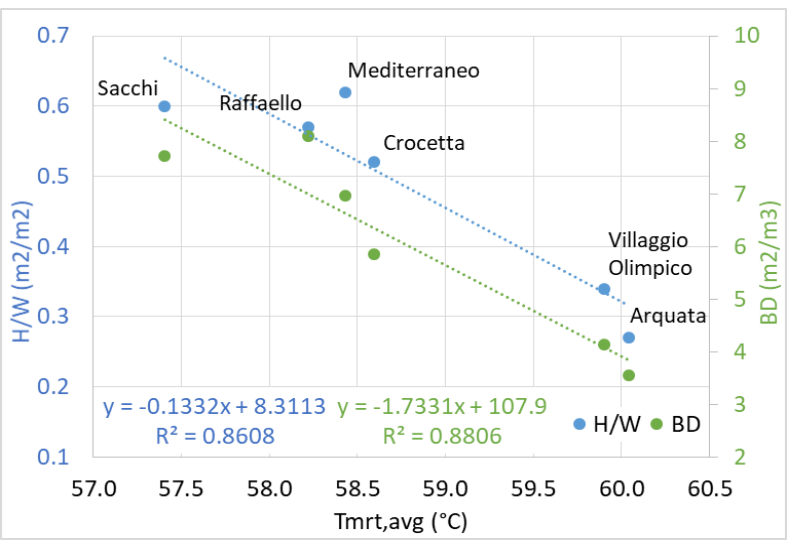

Figure 8. Correlations between urban parameters ( $B D$ and $H / W)$ and the mean radiant temperature $\left(T_{m r t}\right)$

In the second part, average values of the $B D$ and $H / W$ were calculated for each neighborhood, and Figure 8 shows the correlations between the urban parameters and the average $T_{m r t}$ on August $7^{\text {th }}, 2015$ for the six neighborhoods. In particular it is possible to observe that with high values of $B D$ and $H / W$, 
which indicate low distance between buildings, the $T_{m r t}$ tends to decrease, this because this is because the higher and closer the buildings are, the more shadows will be generated. This factor significantly affects mean radiant temperature and thermal comfort conditions. Furthermore, it must be noticed that Turin, compared to other high-urbanized contexts (i.e. New York or Singapore) has relatively low values of $B D$ and $H / W$, therefore there is no pronounced canyon effect, which causes an increase in discomfort.

\section{CONCLUSIONS}

The presented work intends to evaluate thermal comfort conditions at pedestrian level in six neighborhoods with different urban forms in the city center of Turin (Italy) in order to give a support in designing built environments with a high quality of outdoor thermal comfort conditions.

This work investigates indexes and tools used to calculate the thermal comfort conditions, it proposes an analysis on the impact of urban form and green mitigation actions.

The results obtained show how thermal comfort conditions are strongly influenced by both the urban morphology and the presence of green areas and trees. For the city of Turin, which is less built than other densely urbanized cities, the high values of $B D$ and $H / W$ result in better thermal comfort conditions; with lower values thermal comfort conditions could be improved with the use of greenery. The use of urban geometries together with the use of greenery can help urban planners and architects to design better built environments. The use of new indexes and tools as ENVI-met is fundamental to have good results; besides, it is accurate but complex, time consuming and not always all the needed data are available. For many applications a simpler tool could be developed but the comparison of the results with ENVI-met is fundamental.

In future works, thermal comfort conditions will be investigated using simplified GIS-based models that require less input data and with lower simulation times.

\section{REFERENCES}

[1] Detommaso M., Gagliano A., Nocera F. (2019). The effectiveness of cool and green roofs as urban heat island mitigation strategies: A case study, TECNICA ITALIANA-Italian Journal of Engineering Science, 63(2-4): 136-142. https://doi.org/10.18280/ti-ijes.632404

[2] Todeschi, V., Beltramino, S., Jamous, B.E., Mutani, G. (2021). Low-energy architecture for sustainable neighborhoods. TECNICA ITALIANA-Italian Journal of Engineering Science, 65(1): 83-92. https://doi.org/10.18280/ti-ijes.650113

[3] Mutani, G., Todeschi, V. (2020). Low-carbon strategies for resilient cities: A place-based evaluation of solar technologies and green roofs potential in urban contexts. TECNICA ITALIANA-Italian Journal of Engineering Science, 64(2-4): 193-201. https://doi.org/10.18280/tiijes.642-410

[4] Todeschi, V., Mutani, G., Baima, L., Nigra, M., Robiglio, M. (2020). Smart solutions for sustainable cities - The re-coding experience for harnessing the potential of urban rooftops. Applied Sciences, 10(20): 7112. https://doi.org/10.3390/app10207112
[5] Atef, A., Noureddine, Z., Soufiane, F. (2015). SPUCAL_mrt as a new model for estimating the mean radiant temperature in arid lands. Energy Procedia, 74: 273-280. https://doi.org/10.1016/j.egypro.2015.07.603

[6] Coccolo, S., Kämpf, J., Mauree, D., Scartezzini, J.L. (2018). Cooling potential of greening in the urban environment, a step further towards practice. Sustainable Cities and Society, 38: 543-559. https://doi.org/10.1016/j.scs.2018.01.019

[7] Coccolo, S., Pearlmutter, D., Kaempf, J., Scartezzini, J.L. (2018). Thermal comfort maps to estimate the impact of urban greening on the outdoor human comfort. Urban Forestry \& Urban Greening, 35: 91-105. https://doi.org/10.1016/j.ufug.2018.08.007

[8] Mutani, G., Todeschi, V. (2021). Roof-integrated green technologies, energy saving and outdoor thermal comfort: Insights from a case study in urban environment. Planning, $\quad 16(1)$ : 13-23. https://doi.org/10.18280/ijsdp.160102

[9] Naboni, E., Meloni, M., Coccolo, S., Kaempf, J., Scartezzini, J.L. (2017). An overview of simulation tools for predicting the mean radiant temperature in an outdoor space. Energy Procedia, 122: 1111-1116. https://doi.org/10.1016/j.egypro.2017.07.471

[10] Meili, N., Acero, J.A., Peleg, N., Manoli, G., Burlando, P., Fatichi, S. (2021). Vegetation cover and plant-trait effects on outdoor thermal comfort in a tropical city. Building and Environment, 195: 107733. https://doi.org/10.1016/j.buildenv.2021.107733

[11] He, B.J., Ding, L., Prasad, D. (2020). Relationships among local-scale urban morphology, urban ventilation, urban heat island and outdoor thermal comfort under sea breeze influence. Sustainable Cities and Society, 60: https://doi.org/102289. 10.1016/j.scs.2020.102289

[12] Peng, Y., Feng, T., Timmermans, H.J.P. (2019). Expanded comfort assessment in outdoor urban public spaces using Box-Cox transformation. Landscape and Urban Planning, 190: 103594. https://doi.org/10.1016/j.landurbplan.2019.103594

[13] Mazzotta, A., Mutani, G. (2015). Environmental high performance urban open spaces paving: experimentations in Urban Barriera (Turin, Italy). Energy Procedia, 78: 669-674. https://doi.org/10.1016/j.egypro.2015.11.059

[14] Gatto, E., Buccolieri, R., Aarrevaara, E., Ippolito, F., Emmanuel, R., Perronace, L., Santiago, J.L. (2020). Impact of urban vegetation on outdoor thermal comfort: Comparison between a Mediterranean City (Lecce, Italy) and a Northern European City (Lahti, Finland). Forests, 11(2): 228. https://doi.org/10.3390/f11020228

[15] Elwy, I., Ibrahim, Y., Fahmy, M., Mahdy, M. (2018). Outdoor microclimatic validation for hybrid simulation workflow in hot arid climates against ENVI-met and field measurements. Energy Procedia, 153: 29-34. https://doi.org/10.1016/j.egypro.2018.10.009

[16] Evola, G., Costanzo, V., Magrì, C., Margani, G., Marletta, L., Naboni, E. (2020). A novel comprehensive workflow for modelling outdoor thermal comfort and energy demand in urban canyons: Results and critical issues. Energy and Buildings, 216: 109946. https://doi.org/10.1016/J.ENBUILD.2020.109946

[17] Ghaffarianhoseini, A., Berardi, U., Ghaffarianhoseini, A. (2015). Thermal performance characteristics of unshaded courtyards in hot and humid climates. Building 
and Environment, 87: $154-168$ https://doi.org/10.1016/j.buildenv.2015.02.001

[18] Yang, Y., Zhou, D., Wang, Y., Ma, D., Chen, W., Xu, D., Zhu, Z. (2019). Economical and outdoor thermal comfort analysis of greening in multistory residential areas in Xi'an. Sustainable Cities and Society, 51: https://doi.org/101730. 10.1016/j.scs.2019.101730

[19] Mangan, S.D., Oral, G.K., Sozen, I., Kocagil, I.E. (2020). Evaluation of settlement textures in terms of building energy, economic performance, and outdoor thermal comfort. Sustainable Cities and Society, 56: https://doi.org/10.1016/j.scs.2020.102110

[20] Taleghani, M., Kleerekoper, L., Tenpierik, M., Van Den Dobbelsteen, A. (2015). Outdoor thermal comfort within five different urban forms in the Netherlands. Building and Environment, 83: 65-78. https://doi.org/10.1016/j.buildenv.2014.03.014

[21] Taleghani, M., Berardi, U. (2018). The effect of pavement characteristics on pedestrians' thermal comfort in Toronto. Urban Climate, 24: 449-459. https://doi.org/10.1016/j.uclim.2017.05.007

[22] Nasrollahi, N., Namazi, Y., Taleghani, M. (2021). The effect of urban shading and canyon geometry on outdoor thermal comfort in hot climates: A case study of Ahvaz, Iran. Sustainable Cities and Society, 65: 102638. https://doi.org/10.1016/j.scs.2020.102638

[23] Kong, L., Lau, K.K.L., Yuan, C., Chen, Y., Xu, Y., Ren, C., Ng, E. (2017). Regulation of outdoor thermal comfort by trees in Hong Kong. Sustainable Cities and Society, 31: 12-25. https://doi.org/10.1016/j.scs.2017.01.018

[24] Deevi, B., Chundeli, F.A. (2020). Quantitative outdoor thermal comfort assessment of street: A case in a warm and humid climate of India. Urban Climate, 34: 100718. https://doi.org/10.1016/j.uclim.2020.100718

[25] De Abreu-Harbich, L.V., Labaki, L.C., Matzarakis, A. (2015). Effect of tree planting design and tree species on human thermal comfort in the tropics. Landscape and Urban Planning, 138: 99-109. https://doi.org/10.1016/j.landurbplan.2015.02.008

[26] Lam, C.K.C., Cui, S., Liu, J., Kong, X., Ou, C., Hang, J. (2021). Influence of acclimatization and short-term thermal history on outdoor thermal comfort in subtropical South China. Energy and Buildings, 231: 110541. https://doi.org/10.1016/j.enbuild.2020.110541

[27] Paolini, R., Mainini, A.G., Poli, T., Vercesi, L. (2014). Assessment of thermal stress in a street canyon in pedestrian area with or without canopy shading. Energy Procedia, 48:

$1570-1575$ https://doi.org/10.1016/j.egypro.2014.02.177

[28] Lau, K.K.L., Lindberg, F., Rayner, D., Thorsson, S. (2015). The effect of urban geometry on mean radiant temperature under future climate change: a study of three European cities. International journal of biometeorology, 59(7): 799-814. https://doi.org/10.1007/s00484-0140898-1

[29] Nazarian, N., Acero, J.A., Norford, L. (2019). Outdoor thermal comfort autonomy: Performance metrics for climate-conscious urban design. Building and Environment, 155: 145-160. https://doi.org/10.1016/j.buildenv.2019.03.028

[30] Peng, Y., Feng, T., Timmermans, H. (2019). A path analysis of outdoor comfort in urban public spaces. Building and Environment, 148: 459-467. https://doi.org/10.1016/j.buildenv.2018.11.023
[31] Huang, J., Cede, J.G., Spengler, J.D. (2014). CityComfort+: A simulation-based method for predicting mean radiant temperature in dense urban areas. Building and Environment, 80: 84-95. https://doi.org/10.1016/j.buildenv.2014.05.019

[32] Nazarian, N., Fan, J., Sin, T., Norford, L., Kleissl, J. (2017). Predicting outdoor thermal comfort in urban environments: A 3D numerical model for standard effective temperature. Urban Climate, 20: 251-267. https://doi.org/10.1016/j.uclim.2017.04.011

[33] Xiong, Y., Zhang, J., Xu, X., Yan, Y., Sun, S., Liu, S. (2020). Strategies for improving the microclimate and thermal comfort of a classical Chinese garden in the hotsummer and cold-winter zone. Energy and Buildings, 215: 109914 https://doi.org/10.1016/j.enbuild.2020.109914

[34] Biyik, E., Kahraman, A. (2019). A predictive control strategy for optimal management of peak load, thermal comfort, energy storage and renewables in multi-zone buildings. Journal of Building Engineering, 25: 100826. https://doi.org/10.1016/j.jobe.2019.100826

[35] Pantavou, K., Santamouris, M., Asimakopoulos, D., Theoharatos, G. (2014). Empirical calibration of thermal indices in an urban outdoor Mediterranean environment. Building and Environment, 80: 283-292. https://doi.org/10.1016/j.buildenv.2014.06.001

[36] Binarti, F., Koerniawan, M.D., Triyadi, S., Utami, S.S., Matzarakis, A. (2020). A review of outdoor thermal comfort indices and neutral ranges for hot-humid regions. Urban Climate, 31: 100531. https://doi.org/10.1016/j.uclim.2019.100531

[37] Kumar, P., Sharma, A. (2020). Study on importance, procedure, and scope of outdoor thermal comfort-A review. Sustainable Cities and Society, 61: 102297. https://doi.org/10.1016/j.scs.2020.102297

[38] Coccolo, S., Kämpf, J., Scartezzini, J.L., Pearlmutter, D. (2016). Outdoor human comfort and thermal stress: A comprehensive review on models and standards. Urban Climate, 18:

$33-57$. https://doi.org/10.1016/J.UCLIM.2016.08.004

[39] Rodler, A., Guernouti, S., Musy, M., Bouyer, J. (2018). Thermal behaviour of a building in its environment: Modelling, experimentation, and comparison. Energy and Buildings, 168: 19-34. https://doi.org/10.1016/j.enbuild.2018.03.008

[40] Mutani, G., Todeschi, V., Beltramino, S. (2020). Energy consumption models at urban scale to measure energy resilience. Sustainability, 12(14): 5678. https://doi.org/10.3390/su12145678

[41] Höppe, P. (1999). The physiological equivalent temperature-a universal index for the biometeorological assessment of the thermal environment. International Journal of Biometeorology, 43(2): 71-75. https://doi.org/10.1007/s004840050118

[42] Part, V. (2008). I: Environmental meteorology, methods for the human-biometeorological evaluation of climate and air quality for the urban and regional planning at regional level. Part I: Climate. VDI/DIN-Handbuch Reinhaltung der Luft, 29.

[43] Matzarakis, A., Amelung, B. (2008). Physiological equivalent temperature as indicator for impacts of climate change on thermal comfort of humans. In Seasonal Forecasts, Climatic Change and Human Health, 161-172. https://doi.org/10.1007/978-1-4020-6877-5_10 
[44] Walther, E., Goestchel, Q. (2018). The PET comfort index: Questioning the model. Building and Environment, 137:

$1-10$. https://doi.org/10.1016/j.buildenv.2018.03.054

[45] Mutani, G., Carozza, M., Todeschi, V., Rolando, A (2020). Urban-Scale Energy Models: relationship between urban form and energy performance. In 2020 IEEE 3rd International Conference and Workshop in Óbuda on Electrical and Power Engineering (CANDO-
EPE),

pp.

000185-000190.

https://doi.org/10.1109/CANDO-

EPE51100.2020.9337760

[46] Santamouris, M., Ban-Weiss, G., Osmond, P., Paolini, R., Synnefa, A., Cartalis, C., Kolokotsa, D. (2018). Progress in urban greenery mitigation science-assessment methodologies advanced technologies and impact on cities. Journal of Civil Engineering and Management, 24(8): 638-671. https://doi.org/10.3846/jcem.2018.6604 